\title{
Effects of a Nonuniform Tip Clearance Profile on the Performance and Flow Field in a Centrifugal Compressor
}

\author{
Yohan Jung, ${ }^{1}$ Minsuk Choi, ${ }^{2}$ Seonghwan $O h,{ }^{3}$ and Jehyun Baek \\ ${ }^{1}$ Department of Mechanical Engineering, Pohang University of Science and Technology (POSTECH), San 31, Hyoja-dong, \\ Nam-gu, Pohang 790-784, Republic of Korea \\ ${ }_{2}^{2}$ Department of Mechanical Engineering, Myongji University, Yongin 449-728, Republic of Korea \\ ${ }^{3}$ The 7th R\&D Institute, Agency for Defense Development, Daejeon 305-152, Republic of Korea \\ Correspondence should be addressed to Jehyun Baek, jhbaek@postech.ac.kr
}

Received 14 February 2012; Accepted 27 June 2012

Academic Editor: Meinhard Taher Schobeiri

Copyright ( $) 2012$ Yohan Jung et al. This is an open access article distributed under the Creative Commons Attribution License, which permits unrestricted use, distribution, and reproduction in any medium, provided the original work is properly cited.

This paper presents a numerical investigation of the effects of a nonuniform tip clearance profile on the performance and flow field in a centrifugal compressor with a vaneless diffuser. This study focuses in particular on the magnitude and location of the wake. Six impellers with different tip clearance profiles were tested in the flow simulations. The accuracy of the numerical simulations was assessed by comparing the experimental data with the computational results for a system characterized by the original tip clearance. Although the performance improved for low tip clearances, a low tip clearance at the trailing edge improved the compressor performance more significantly than a low tip clearance at the leading edge. The flow field calculated for a system characterized by a low tip clearance at the trailing edge produced a more uniform velocity distribution both in the circumferential and in the axial directions at the impeller exit because the wake magnitude was reduced. As a consequence, this impeller provided a better potential for diffusion processes inside a vaneless diffuser.

\section{Introduction}

Centrifugal compressors used in aeronautical and industrial applications are required to function at high pressure ratios and over wide operating ranges. A better understanding of the flow mechanism underlying the secondary flow fields inside compressors is essential for the design of centrifugal compressors with improved performance and extended operational ranges [1]. The main flow in centrifugal compressors is sensitive to secondary flows generated by the channel curvature as well as the centrifugal and Coriolis forces. As a result, jet-wake flow patterns form at the impeller exit, and these patterns govern the flow field in the diffuser $[2,3]$. In the jet-wake model, flow in the jet region near the pressure surface of the blade is nearly loss-free, whereas flow in the wake region near the suction surface of the blade generates large total pressure losses. The classical jet-wake model ignores the influence of the tip clearance flow and the spanwise flow variations. The model, therefore, does not adequately describe the outlet flow of an unshrouded impeller with tip clearance, and the model must be revised. In unshrouded impellers, the tip clearance flow significantly affects the performance and flow field because it causes pressure losses over the tip clearance and strengthens the secondary flows.

The influence of the tip clearance flow on the performance and flow structure in centrifugal compressors has been studied by many researchers [4-14]. In previous studies, it was found that the swirling flows and vortex motions within unshrouded impellers are sensitive to the tip clearance flow. Consequently, these flows produce high losses and degrade performance if the tip clearance is large. The nonuniformity of the impeller outlet flow due to the tip clearance flow significantly affects the diffuser inlet flow conditions and causes large flow separations inside the diffuser. The overall compressor performance may be improved by enhancing the uniformity of the impeller outlet flow in the circumferential and axial directions. Most previous numerical studies of the tip clearance effects have assumed a uniform 


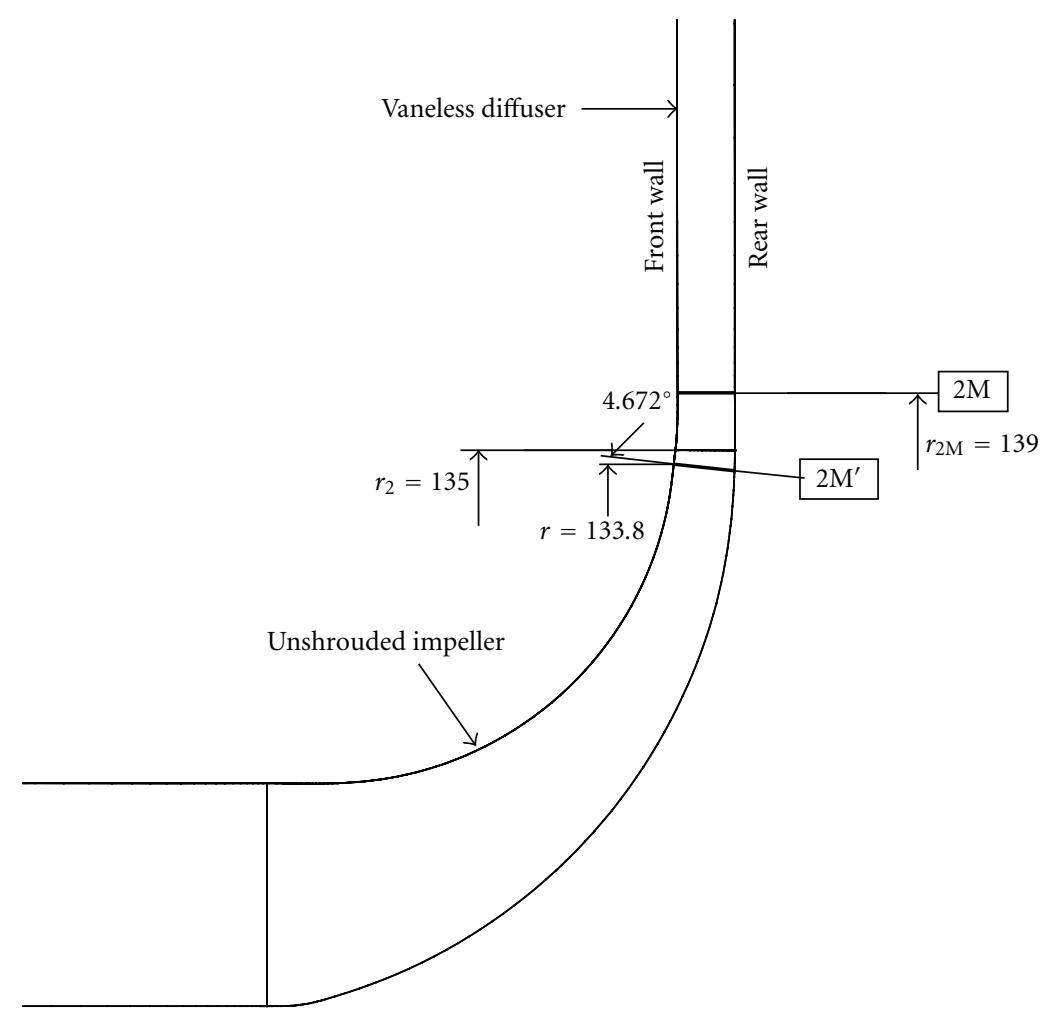

FIgURE 1: Geometrical configuration and measurement sections.

tip clearance with a constant height. Few studies have considered a nonuniform tip clearance.

The main objective of this work is to numerically investigate the effects of various nonuniform tip clearance specifications on the performance and flow field in a centrifugal compressor, particularly focusing on the magnitude and location of the wake region. Numerical simulations were conducted for six centrifugal compressor impellers in which the tip clearance height varied linearly from the leading to the trailing edge. The numerical results were compared with experimental data to assess the accuracy of the numerical predictions.

\section{Test Compressor Description}

The compressor used in this study is known as the "Radiver" in the literature. Radiver test case measurements were conducted at the Institute of Jet Propulsion and Turbomachinery at RWTH Aachen, Germany. The investigations were funded in part by the Deutsche Forschungsgemeinschaft (DFG). The experimental data were made available to the public for broad use in computational fluid dynamics (CFD) validation studies. The compressor stage consists of an unshrouded impeller with 15 backswept blades and a vaneless diffuser. Under the design condition with a specific speed of 0.69 , the maximum total pressure ratio and the maximum corrected mass flow rate through the impeller are 4.07 and $2.5 \mathrm{~kg} / \mathrm{s}$, respectively. The tip clearance height is $0.7 \mathrm{~mm}$ for the stationary impeller, and the vaneless diffuser has a constant
TABLe 1: Geometrical specification.

\begin{tabular}{lcc}
\hline & Impeller \\
\hline Number of blades & & 15 \\
Blade backsweep angle & $38^{\circ}$ \\
Exit radius & $135 \mathrm{~mm}$ \\
Inlet hub radius & $30 \mathrm{~mm}$ \\
Inlet shroud radius & $72.9 \mathrm{~mm}$ \\
Exit blade height & $11 \mathrm{~mm}$ \\
\hline & Diffuser \\
\hline Constant diffuser height & & $11.1 \mathrm{~mm}$ \\
Exit radius & & $345 \mathrm{~mm}$ \\
\hline
\end{tabular}

meridional height of $11.1 \mathrm{~mm}$. The geometrical specifications are summarized in Table 1 , and a schematic diagram of the meridional plane is shown in Figure 1, where the sections $2 \mathrm{M}$ and $2 \mathrm{M}^{\prime}$ indicate the measurement positions. A complete description of the geometrical configurations and operating conditions can be found in Ziegler et al. [15-17].

\section{Numerical Procedure}

Three-dimensional simulations were performed using the commercial CFD code, ANSYS CFX 12.0. Steady calculations were conducted to minimize the computational effort. As numerical scheme for these calculations, a second-order upwind scheme was used in space. The computational 


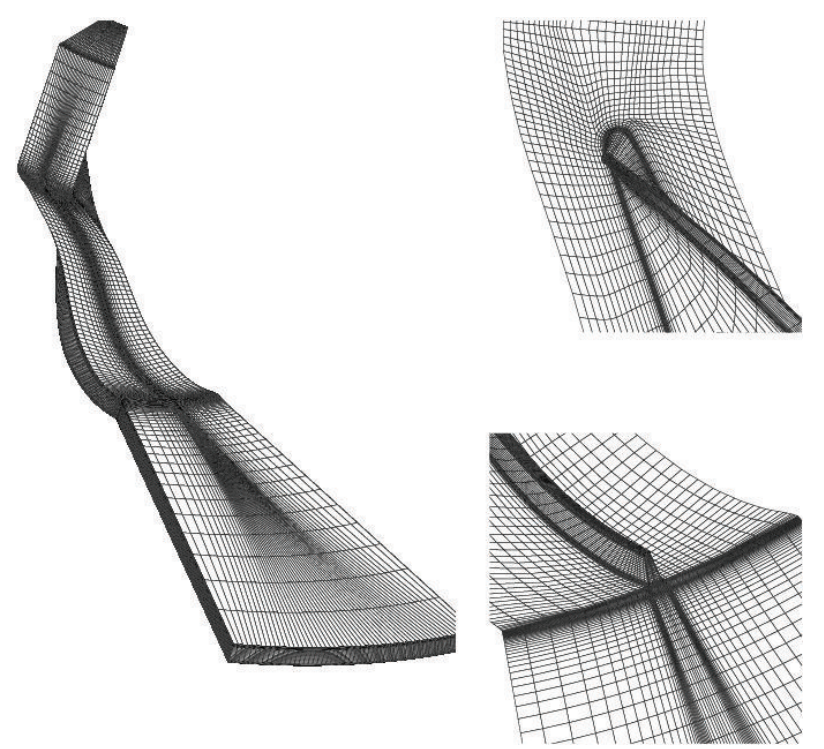

Figure 2: Computational grid for the entire domain, with the leading and trailing edges presented in detail.

domain consisted of a single impeller blade passage and a vaneless diffuser, in which an $\mathrm{H}$-type grid was employed over the regions of the main flow channel and the tip clearance. An O-type grid was used around the impeller blade to improve the grid quality near the leading and trailing edges of the blade. The grid-independence study was performed at three different grid sizes of 103818,608170 , and 1196 420 cells at $\phi / \phi_{d}$ of 1.0. There was no significant difference (less than $0.2 \%$ ) between the medium and large grid size regarding total pressure ratio and total efficiency. As a result of the grid-independence study, the medium grid size was selected to perform flow analysis. 15 cells in the spanwise direction were used to study the flow field within the impeller tip clearance region. The total number of computational cells is approximately 450000 in the impeller passage and 150000 in the diffuser. The computational grid over the entire domain, including the detailed surface grid near the leading and trailing edges of the impeller blade, is shown in Figure 2.

The $k-\omega$ SST model was applied to obtain turbulent quantities, assuming that the flow in the compressor is fully turbulent. In most of the blade surfaces and end walls, $y+$ values are less than 2 as required for the use of $k-\omega$ SST model. The design rotational speed was $35200 \mathrm{rpm}$. The total pressure, total temperature, and flow direction were specified at the impeller inflow boundary $\left(P_{01}=101300 \mathrm{~Pa}\right.$ and $T_{01}=288.15 \mathrm{~K}$ ), and the mass flow rate was specified at the diffuser outflow boundary. Periodic boundary conditions were applied in the circumferential direction, and the walls were treated with the no-slip and adiabatic conditions.

\section{Numerical Test Cases}

The influences of a nonuniform tip clearance on the performance and flow field were investigated by conducting simulations of impellers with six tip clearance shapes. The
TABle 2: Numerical test cases.

\begin{tabular}{lcc}
\hline & Leading edge & Trailing edge \\
\hline Case 1 & $0.7 \mathrm{~mm}$ & $0.7 \mathrm{~mm}$ \\
Case 2 & $0.7 \mathrm{~mm}$ & $0.48 \mathrm{~mm}$ \\
Case 3 & $0.7 \mathrm{~mm}$ & $0.24 \mathrm{~mm}$ \\
Case 4 & $0.48 \mathrm{~mm}$ & $0.7 \mathrm{~mm}$ \\
Case 5 & $0.24 \mathrm{~mm}$ & $0.7 \mathrm{~mm}$ \\
Case 6 & $0.24 \mathrm{~mm}$ & $0.24 \mathrm{~mm}$ \\
\hline
\end{tabular}

tip clearance heights at the leading and trailing edges were selected, and the distribution of the tip clearance varied linearly along the tip. To account for reductions in the tip clearance due to centrifugal forces and temperature variations under hot-running conditions [17], the tip clearances at the leading and trailing edges were varied from $0.7 \mathrm{~mm}$ to $0.48 \mathrm{~mm}$ or $0.24 \mathrm{~mm}$. The relative clearance ratios, defined as the ratio of the tip clearance height to the blade height at the impeller exit, are $6.4 \%, 4.4 \%$, and $2.2 \%$ for $0.7 \mathrm{~mm}, 0.48 \mathrm{~mm}$, and $0.24 \mathrm{~mm}$, respectively. Table 2 shows the numerical test cases. The tip clearance at the trailing edge was varied in cases 2 and 3, whereas the tip clearance at the leading edge was varied in cases 4 and 5 . The tip clearance both at the leading and trailing edges was varied in case 6 . The computational conditions, grid size, and boundary conditions were constant for all test cases except for the tip clearance profile.

\section{Validation for Uniform Tip Clearance}

Prior to comparing the performance of the test cases, the numerical result for the original tip clearance $(0.7-0.7 \mathrm{~mm})$ was validated with the experimental data. Because no experimental data is available under $100 \%$ speed condition, all calculations were performed at $80 \%$ speed. Measurements were carried out with steady probes and time resolving laser2 -focus velocimeter at sections $2 \mathrm{M}$ and $2 \mathrm{M}^{\prime}$, respectively. Numerical results were validated by comparing the computed characteristic curves of the mass-averaged static and total pressures in section $2 \mathrm{M}$ with the experimental data, as shown in Figure 3. The CFD results showed satisfactory agreement with the experimental results over the full range of operating conditions. The flow field at section $2 \mathrm{M}^{\prime}$ near the impeller exit is shown in Figure 4 at $\phi / \phi_{d}$ of 1.0. The overall flow structure predicted by the numerical simulations, including the jet-wake flow pattern, was qualitatively well captured, as observed by comparison with the experimental results. Some differences were present in the low meridional velocity region near the shroud. The extension of the low meridional velocity region along the axial direction away from the shroud was overpredicted by CFD due to a higherintensity tip clearance flow, which was caused by a uniform tip clearance. Improved results may be obtained by applying a nonuniform tip clearance height $(0.7-0.48 \mathrm{~mm})$ [13]

\section{Results}

6.1. Performance Prediction. Three-dimensional calculations were performed over the full operating range, from near-stall 


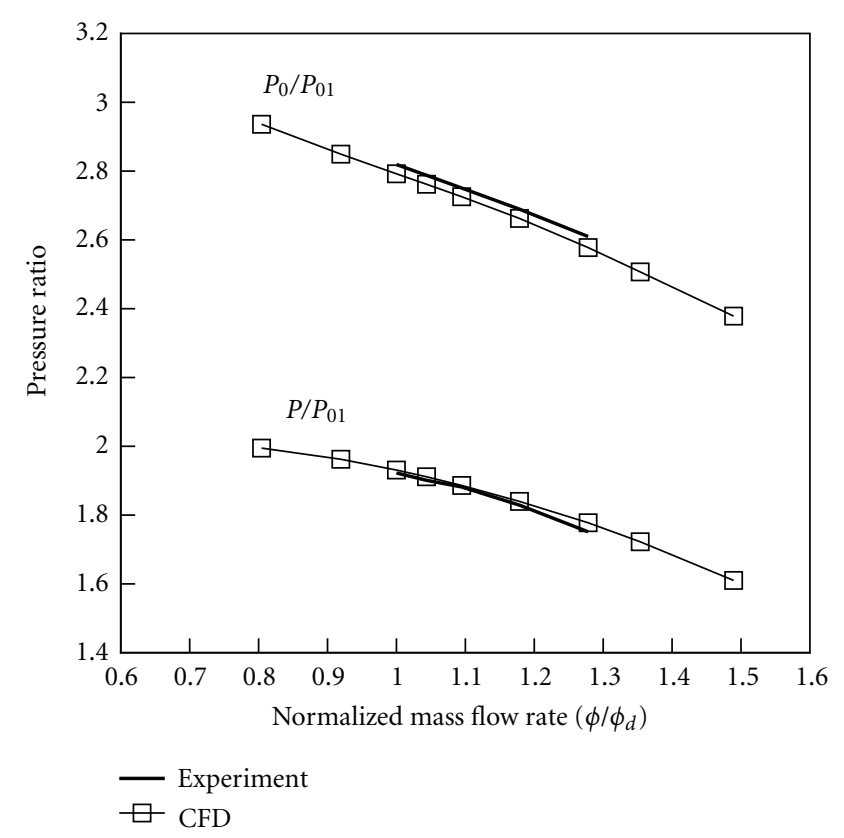

Figure 3: Comparison of the static and total pressure characteristic curves at section $2 \mathrm{M}$.

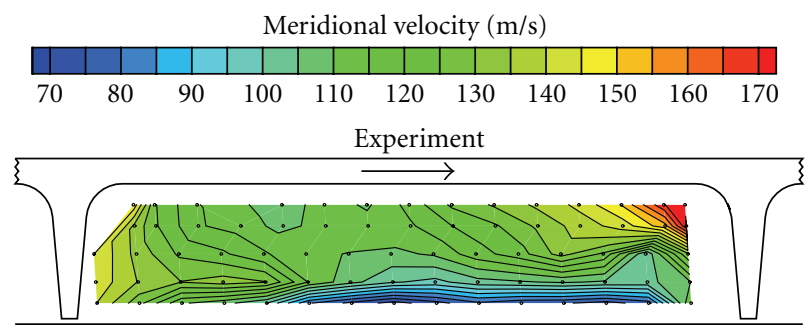

CFD

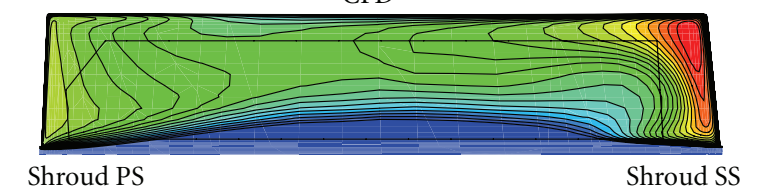

Figure 4: Comparison of the meridional velocity at section $2 \mathrm{M}^{\prime}$ at $\phi / \phi_{d}$ of 1.0 .

conditions to choked points. The overall performances were compared.

The static and total pressure ratios at the impeller exit are shown in Figure 5. The static pressures over the entire operating range for all impellers with reduced tip clearances were higher than those in the original case, indicating that reductions in the tip clearance at the leading or trailing edge improved the static pressure rise. The impeller exit total pressure also increased for the impellers with reduced tip clearances. Case 6 had the highest static and total pressures among the test cases, because the tip clearance was reduced both at the leading and trailing edges. At $\phi / \phi_{d}$ of 1.0, cases 3 and 6 showed $2.5 \%$ and $3.9 \%$ improvements in the static pressure rise compared to case 1 , respectively. The static and total pressure curves also indicated that a smaller tip clearance at the trailing edge was more effective than a smaller tip clearance at the leading edge. Large total pressure losses generally result from leakage flow through the tip gap [5]. As the tip clearance height at the leading or trailing edge is reduced in size, reductions in the tip leakage flow decrease losses and improve pressure rises. In the original case, at $\phi / \phi_{d}$ of 0.8 , the tip leakage flow rate was $5 \%$ lower than that at $\phi / \phi_{d}$ of 1.0 , while the mass flow rate was $20 \%$ lower than that at $\phi / \phi_{d}$ of 1.0. Because the mass flow rate through the impeller was reduced much more than the mass flow rate through the tip, the influence of the tip clearance flow was not reduced at $\phi / \phi_{d}$ of 0.8. Therefore, the decreased tip clearance was still effective even at the lower mass flow rate.

The performance of a centrifugal compressor is significantly affected by tip clearance in two ways. First, tip leakage flow causes large pressure losses due to mixing with the main passage flow, as mentioned above. Second, the impeller cannot transfer its momentum to the fluid across the tip clearance, which decreases the total work input. Consequently, small changes in the tip clearance could have large influences on the compressor performance. The work input coefficient $\left(\mu=C_{\theta 2} / U_{2}\right)$ at the impeller exit is shown in Figure 6. Higher work input coefficients were associated with all impellers with tip clearances smaller than that of the original case. Additionally, decreasing the tip clearance at the trailing edge rather than at the leading edge effectively increased the work input.

The shapes of the total efficiency curves for all cases resembled the original case, with a maximum peak at $\phi / \phi_{d}$ of 1.0, as shown in Figure 6. The impellers with reduced tip clearances yielded better efficiencies because the mixing loss caused by the tip clearance flow was reduced. In particular, cases 3 and 6 showed $1.2 \%$ and $2.2 \%$ improvements in efficiency compared to case 1 at the design point, respectively. At low mass flow rates, the total efficiency difference between cases 1 and 3 decreased compared to the peak-efficiency point, probably because the mixing loss due to the tip clearance was less prominent.

The diffuser performance was investigated by measuring the static and total pressure ratios at the vaneless diffuser exit, as shown in Figure 7. The overall characteristics of the diffuser exit pressures were similar to those of the impeller exit pressures. It was evident that case 6 had higher static and total pressure ratios than any other cases. In addition, cases 2 and 3 , which featured reduced tip clearances at the trailing edge, were clearly superior to cases 4 and 5 , which featured reduced tip clearances at the leading edge, with regards to the static and total pressures at the diffuser exit.

6.2. Flow Field Analysis. The flow field was analyzed to investigate the performance variations caused by the reduced tip clearance at the leading or trailing edges. The flow field comparison was confined to the operating condition at $\phi / \phi_{d}$ of 1.0, under which a higher efficiency was observed for cases $1,3,5$.

6.2.1. Tip Leakage Flow. Variations in the normalized flow velocity through the tip clearance from the leading edge to 

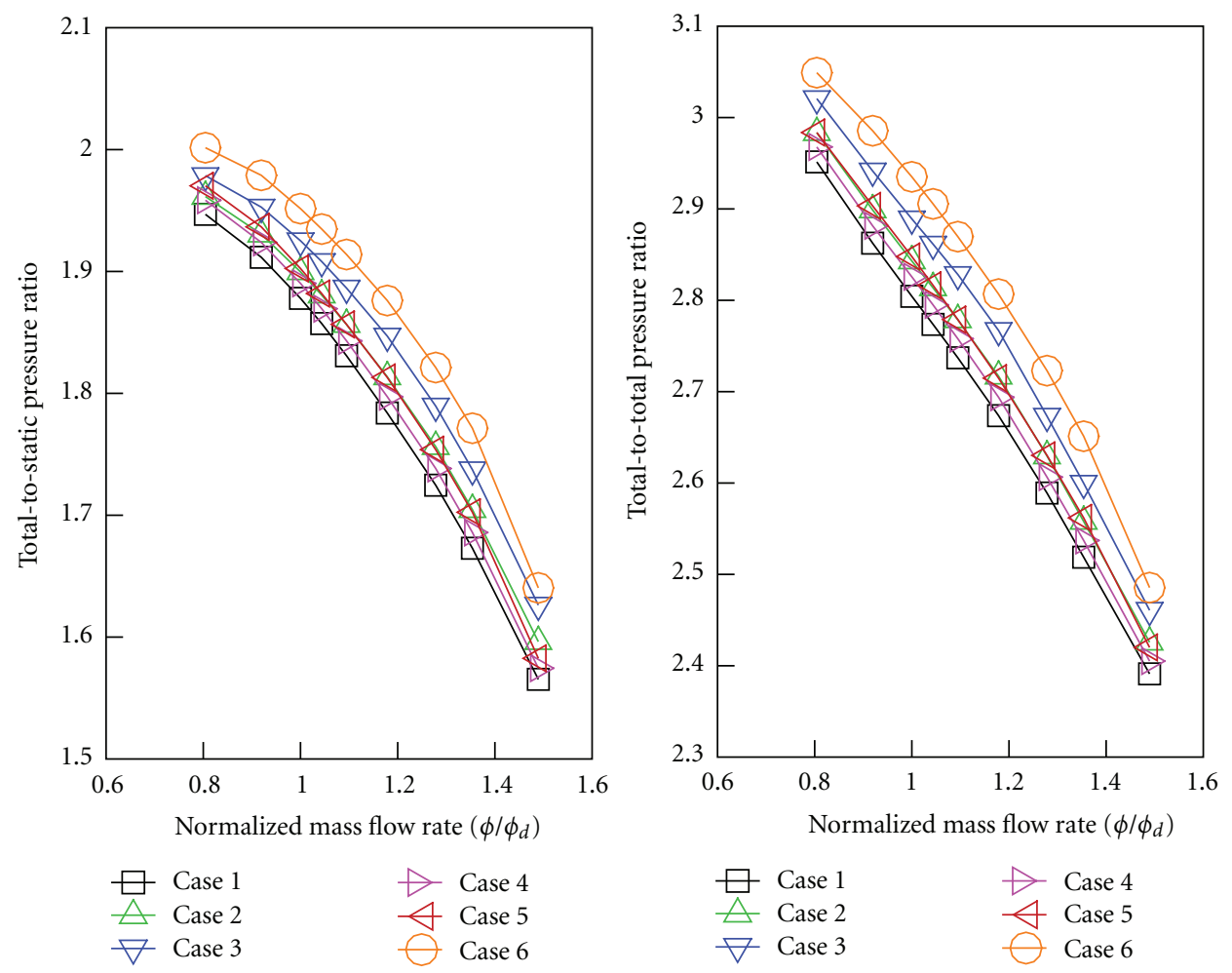

FIGURE 5: Impeller exit static and total pressure ratio.
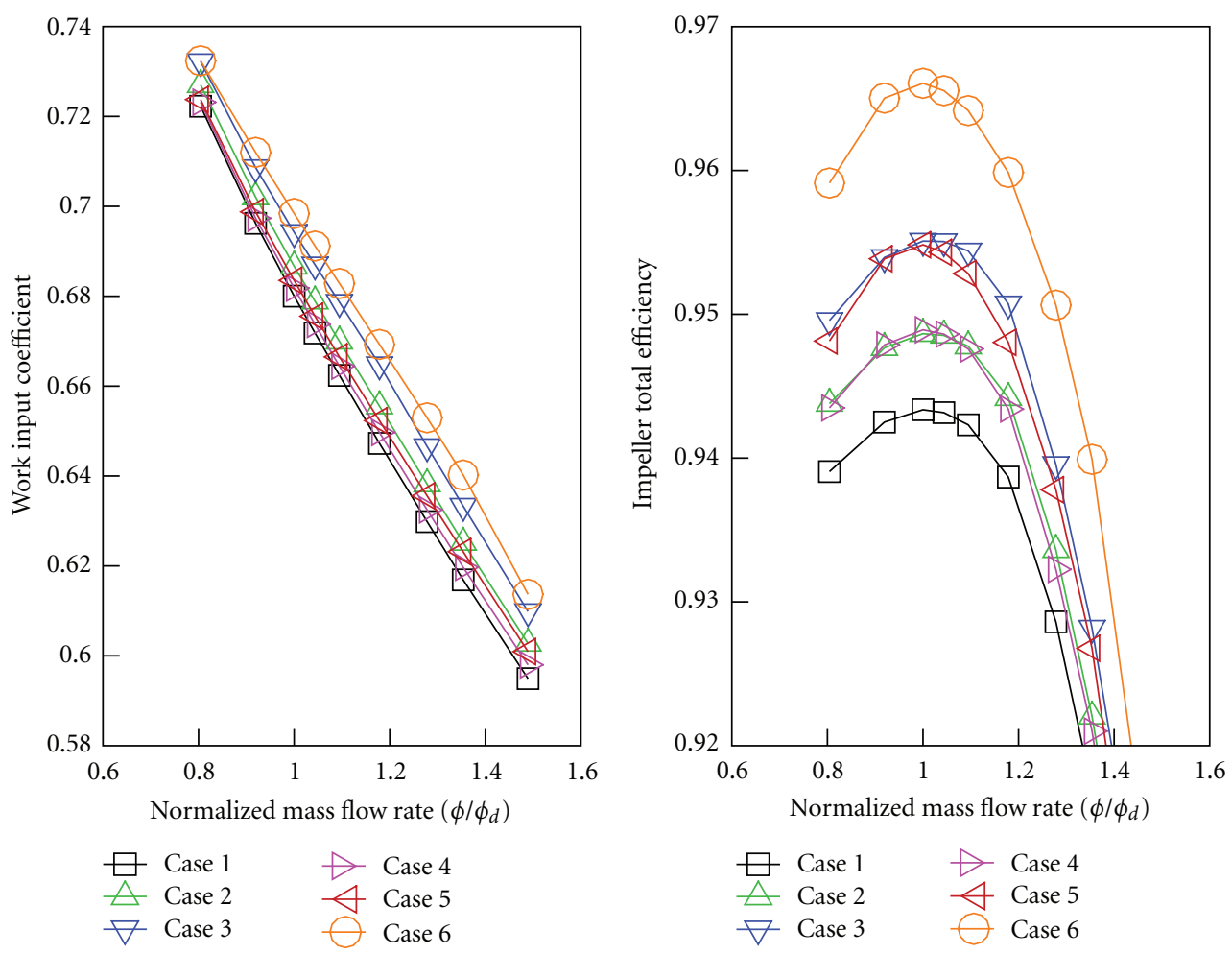

FIGURE 6: Impeller work input coefficient and total-to-total efficiency. 

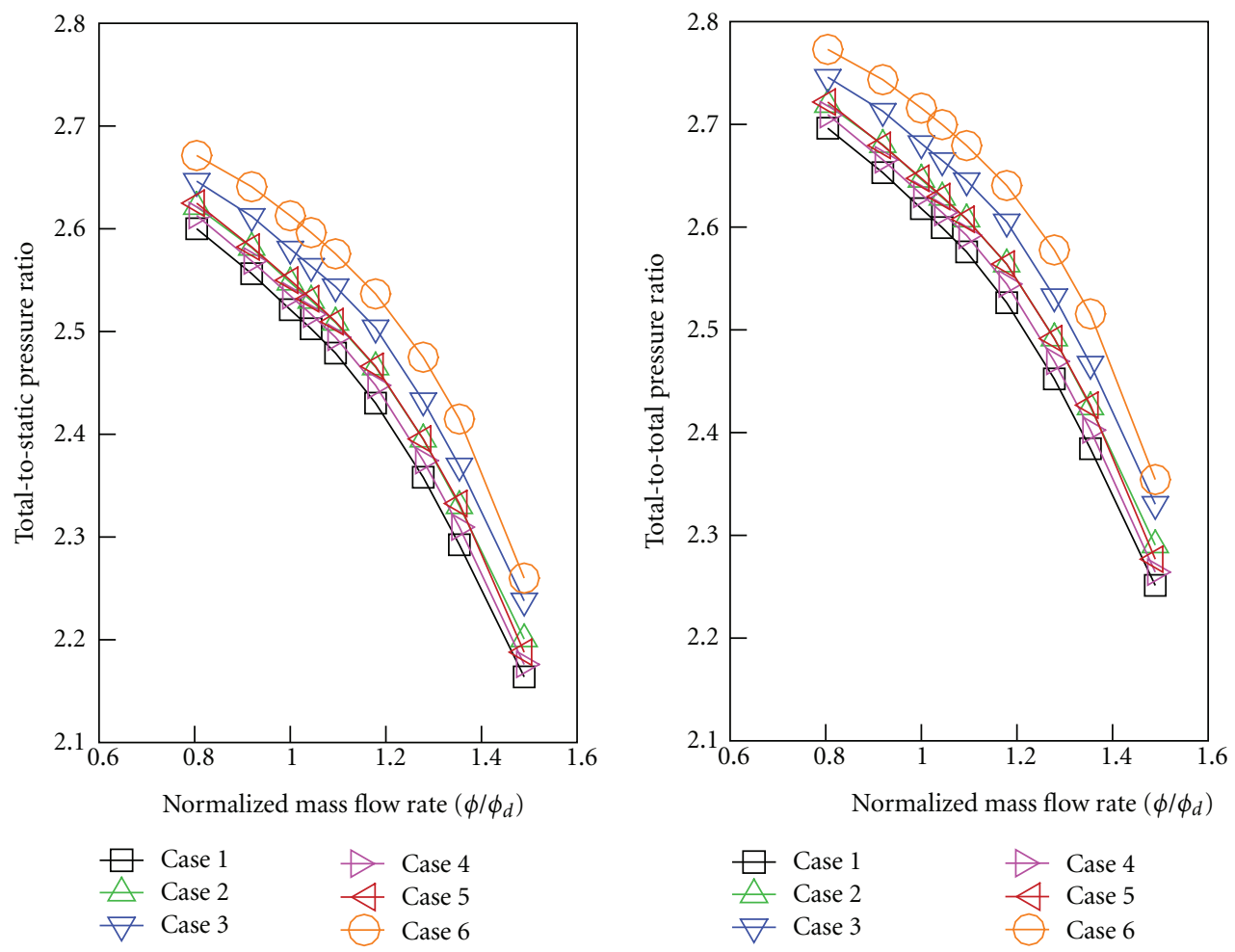

FIgURE 7: Diffuser exit static and total pressure ratio.

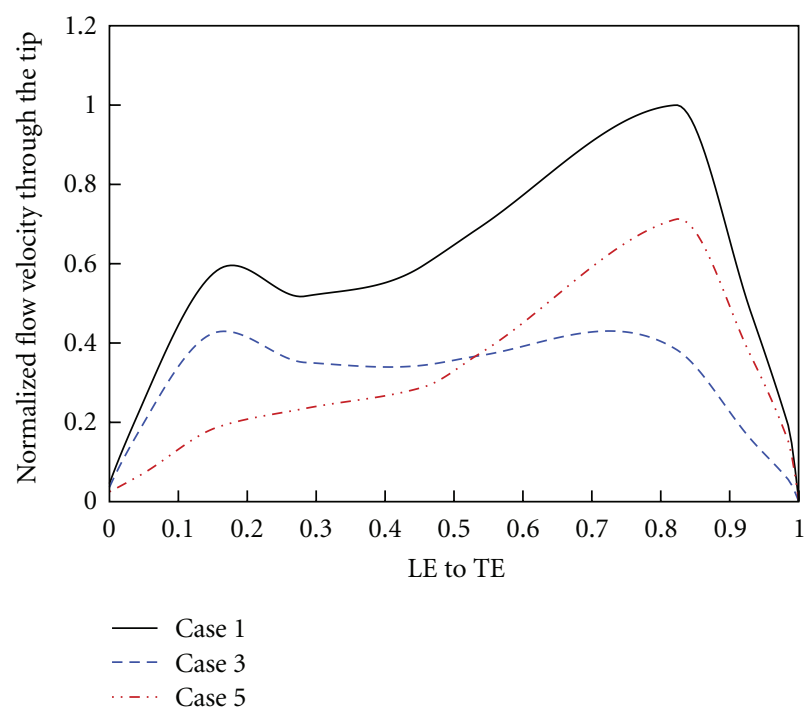

Figure 8: Normalized flow velocity through the tip.

the trailing edge are shown in Figure 8. Relative to case 1, the flow velocity along the blade chord clearly decreased for cases 3 and 5 . In case 1 , the tip leakage flow velocity distribution had local maxima at $20 \%$ and $80 \%$ chord lengths. In case 3 , the flow velocity increased from the leading edge to a maximum at $20 \%$ chord length, then it retained a nearly constant value until $80 \%$ chord length. This result indicated that case 3 experienced a significant reduction in the tip leakage flow in the rear region due to the smaller tip clearance at the trailing edge. On the other hand, case 5 displayed a slow increase in the tip leakage flow from the leading edge to $80 \%$ chord length, where the tip leakage flow velocity reached a local maximum value. In contrast with case 5, case 3 displayed a larger flow velocity across the gap in the front region but a smaller flow velocity in the rear region. The total flow rate integrated along the chord length in case 3 was lower than that in case 5 . The flow rate across the tip in cases 3 and 5 were reduced to $69 \%$ and $73 \%$, respectively, of the value in case 1 . These flow velocity variations significantly affected the flow field and were closely related to the lower total pressure loss.

6.2.2. Blade Tip Loading. The effects of the tip clearance distribution on the blade tip loading were investigated by comparing the blade pressure distributions near the shroud in the three cases. Figure 9 shows a plot of the blade tip loading values at $90 \%$ span from the hub. All three cases showed similar pressure distributions along the blade chord. However, at 30\% chord length from the leading edge, case 5 showed the highest blade loading, suggesting that the generation of a tip leakage vortex was delayed because the mass flow rate across the tip clearance decreased significantly in the front part of the blade due to the small tip clearance at the leading edge. On the other hand, after 75\% chord length, the static pressure increase on the pressure surface for case 3 was much larger than it was for the other cases, and it generated higher blade tip loading in the rear region. This result arose from the fact that case 3 had a small tip clearance 


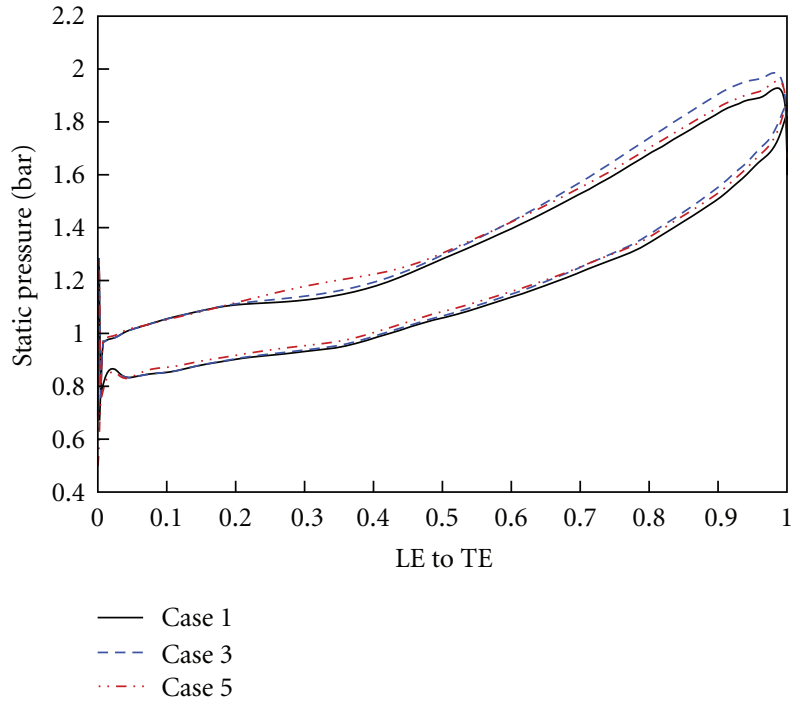

FIGURE 9: Blade pressure distribution at 90\% span.

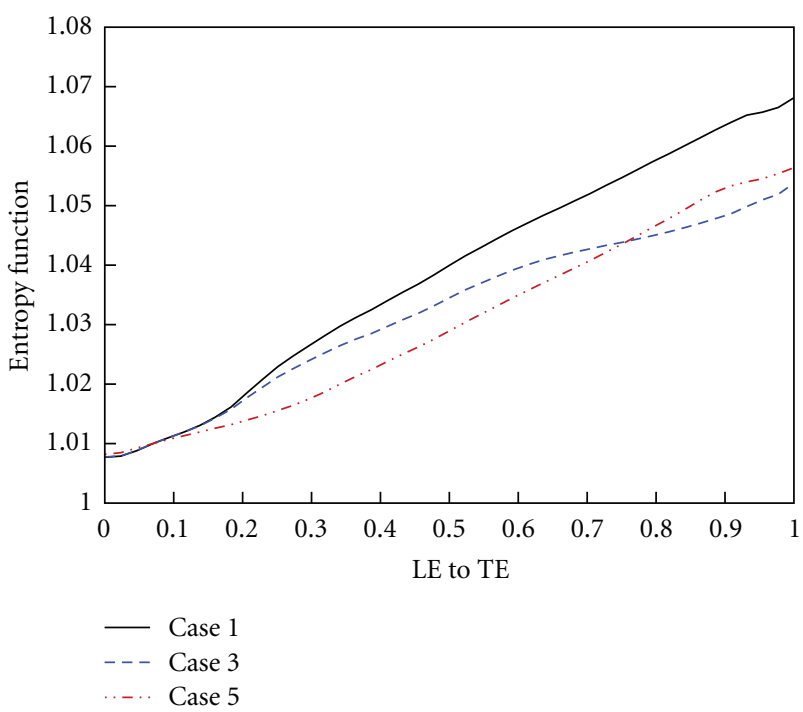

FIGURE 10: Entropy function distribution along the blade chord.

at the trailing edge, which produced a weak tip leakage flow and decreased the mixing loss.

6.2.3. Loss Generation Process. The loss distribution in the impeller was investigated by calculating the entropy function using (1), as suggested by Whitfield and Baines [18]. The entropy function distributions from the leading edge to the trailing edge are shown in Figure 10,

$$
\sigma=e^{\Delta s / R}=\frac{\left(T_{0} / T_{01}\right)^{\gamma /(\gamma-1)}}{\left(P_{0} / P_{01}\right)} .
$$

The slope of the entropy function was nearly constant for the impeller with a uniform tip clearance (case 1), whereas the entropy function for impellers with nonuniform tip clearances (cases 3 and 5) was non-linear. Variations

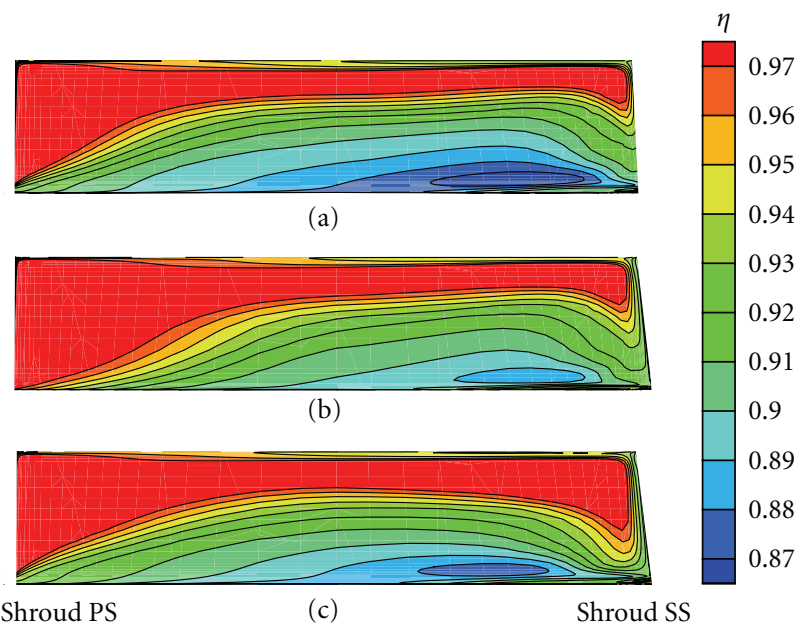

FIGURE 11: Total-to-total efficiency distribution at the impeller exit: (a) Case 1, (b) Case 3, and (c) Case 5.

in the entropy slope were related to the tip clearance loss changes caused by the nonuniform tip clearance. Stronger interactions between the tip leakage flow and the main passage flow occurs at the point at which the tip leakage flow is stronger. At such points, the flow interaction is strong, which increases the mixing loss and deteriorates the compressor performance. The entropy function of case 3 had a steep slope in the front region but a shallow slope in the rear region rather than that for case 5. As a consequence, the entropy function of case 3 was lower at the trailing edge than it was in case 5. Because the entropy function at the impeller exit represents the accumulated total loss through the flow passage, the low entropy in case 3 produced a higher impeller efficiency, as shown in Figure 6. This result indicated that the positive effects of loss reduction in the rear region of case 3 were more dominant than the loss gains in the front region. The tip clearance losses were quantitatively compared by calculating the total pressure loss coefficient induced by the tip clearance using the following equation [19]:

$$
\bar{\omega}_{\mathrm{CL}}=\frac{2 \dot{m}_{\mathrm{CL}} \Delta p_{\mathrm{CL}}}{\left(\dot{m} \rho_{1} W_{1}^{2}\right)} .
$$

The overall total pressure loss in case 3 was $3.4 \%$ lower than that of case 5 and $29 \%$ lower than that of case 1 . Consequently, the tip clearance loss can be decreased more effectively by reducing the tip clearance at the trailing edge.

6.2.4. Impeller Outlet Flow. The total efficiency distributions at the impeller outlet planes are shown in Figure 11. The efficiency distributions of all three cases showed similar high efficiency flow patterns near the pressure side and low efficiency flow patterns near the suction side of the shroud, which are typical properties of centrifugal compressors [20]. The magnitude and extent of the low efficiency regions differed to some degree. The low efficiency region near the shroud suction side in case 1 was most extended both in the circumferential and in the axial directions compared with the other two cases because the tip leakage flow was the 


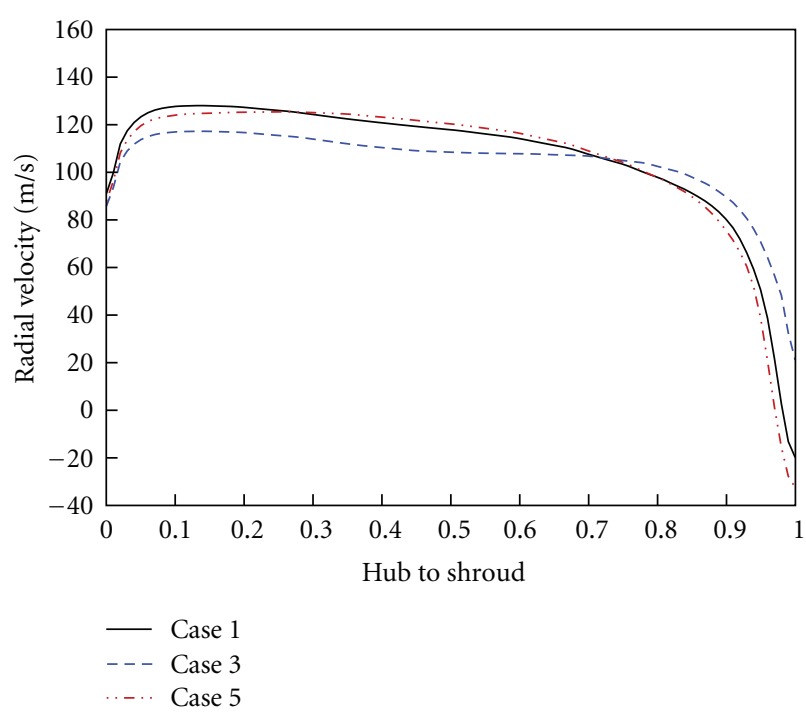

Figure 12: Radial velocity distribution from hub to shroud at the impeller exit.

strongest in case 1 . The magnitude and extent of the low efficiency region in case 5 were significantly lower than in case 1 , and further reductions in the low efficiency region were achieved in case 3. Variations in the high loss region contributed significantly to the reduced performance at the impeller exit. It should be noted that the tip clearance height at the trailing edge was a main factor in determining the high loss region near the shroud at the impeller exit.

A comparison of the circumferentially averaged radial velocity distributions from the hub to the shroud at the impeller exit is plotted in Figure 12. At the impeller exit, the flow near the shroud experiences secondary flows that block the flow passage. In addition, the tip clearance flow influences the secondary flow structure and further blocks the flow passage, thereby generating a large total pressure loss near the shroud. The blockage resulted in a rapid decrease in the radial velocity near the shroud in all three cases. The low radial velocity near the shroud indicated a separated zone in which a high loss fluid accumulated. A blocked zone with a negative radial velocity was present above $98 \%$ span from the hub in cases 1 and 5, suggesting that a strong reverse flow was present near the shroud because low momentum flow could not overcome the pressure gradient in the radial direction. However, in case 3, no reverse flow was observed near the shroud, suggesting that the blockage was smaller in case 3 than in the other two cases. For this reason, case 3 included the smallest high-loss region near the shroud, as shown in Figure 11. The increased radial velocities near the shroud in case 3 were explained by the reduced tip leakage flow in the rear region, as confirmed in Figure 8. The radial velocity distributions in cases 1 and 5 were almost identical, even though these systems included different tip clearances at the leading edge. This result suggested that the radial velocity distribution in the spanwise direction at the impeller exit depended strongly on the tip clearance at the trailing edge.

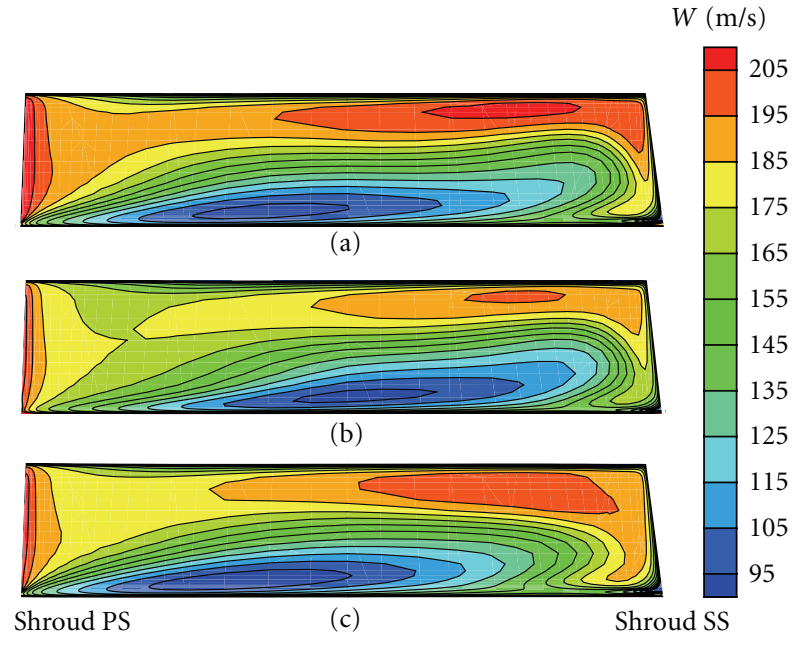

FIGURE 13: Relative velocity distribution at the impeller exit: (a) Case 1, (b) Case 3, and (c) Case 5.

6.2.5. Wake Flow. The wake formation at the impeller exit was investigated by comparing the relative velocity distributions in the three cases, as shown in Figure 13. All three cases showed a strongly nonuniform flow both in the circumferential and in the axial directions, and the flow structure was highly three-dimensional at the impeller exit. In addition to the axial flow variations due to the skewed shear layer, the flow was affected in the circumferential direction by the blade loading. The relative velocity distributions in cases 1 and 5 showed similar qualitative characteristics. Case 3 presented a different flow structure in the wake region, which included an area of low relative velocity.

The circumferential nonuniformity at the impeller exit was investigated by comparing the relative deviations from the mass-averaged relative velocity at $90 \%$ span for the three cases, as shown in Figure 14. The absolute magnitude of the deviations in case 3 was smaller than that in the other cases in the region from the pressure side to the mid-pitch, which led to an enhanced uniformity in the flow field in the circumferential direction. Another important feature is the location of the wake region, where the relative velocity deviation has the minimum value. The wake region appeared near the pressure side in cases 1 and 5, but it was closer to the center of the blade pitch in case 3 .

To determine the source of movement of the wake region, the secondary vorticity distribution at the impeller exit was calculated using the following equation, and the results are shown in Figure 15:

$$
\mathrm{SV}=\frac{\omega}{\Omega} \cdot \frac{C}{|C|}, \quad \omega=\nabla \times C .
$$

The sign of the secondary vorticity indicated the rotational direction of the secondary flow, where positive values corresponded to vortices rotating in the counter-clockwise direction and negative values corresponded to vortices rotating in the clockwise rotation. Two distinct vortices were observed in all three cases. The vortex with a positive secondary vorticity generated by the Coriolis force, called 


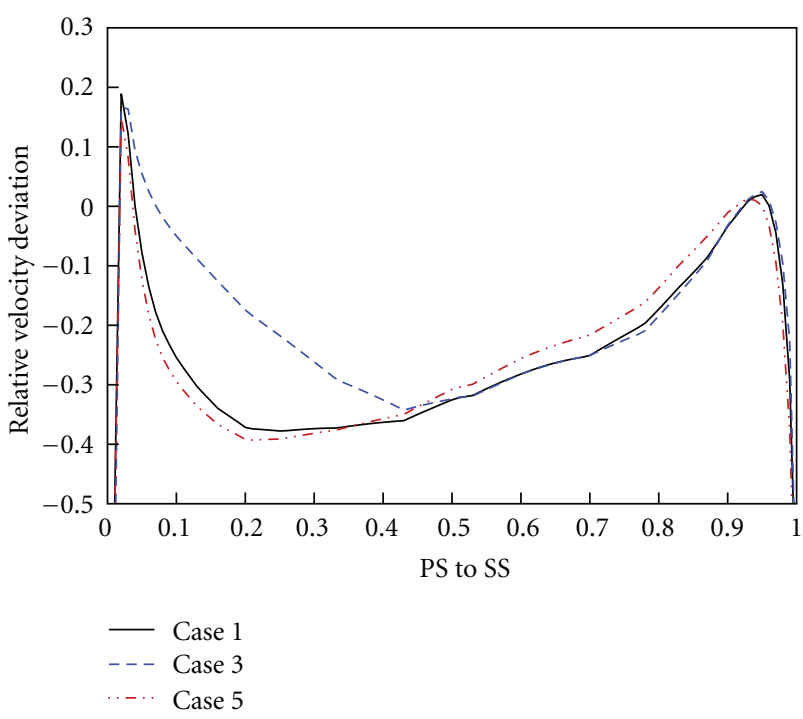

FIGURE 14: Relative deviation of relative velocity from PS to SS at the impeller exit (90\% span).

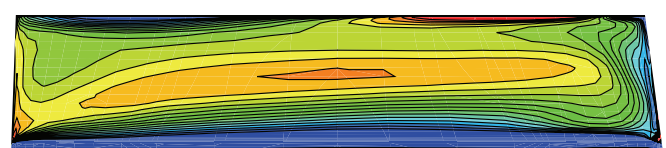

(a)

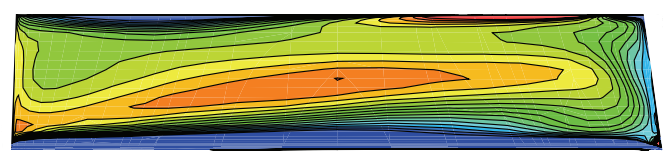

(b)

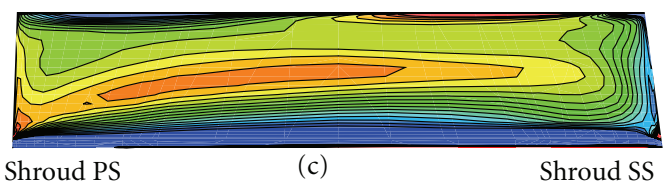

FIGURE 15: Normalized secondary vorticity distribution at the impeller exit: (a) Case 1, (b) Case 3, and (c) Case 5.

the passage vortex, moved low momentum fluid above the mid-span from the pressure to the suction side. On the other hand, the tip leakage vortex with a negative secondary vorticity moved low momentum fluid near the shroud from the suction to the pressure side. Interactions between these two vortices rotating in opposite directions affected the location of the wake region near the shroud. In cases 1 and 5, the tip leakage vortex was stronger than the passage vortex, so that the transport of low-energy fluid to the suction side was limited. This explained why the wake region was located near the pressure side in cases 1 and 5 , as shown in Figure 14. In case 3 , however, the intensity of the tip leakage vortex decreased due to the reduced tip clearance at the trailing edge. Therefore, the passage vortex became large and was not hampered by the tip leakage vortex, which further transported the low-energy fluid toward the suction side. In

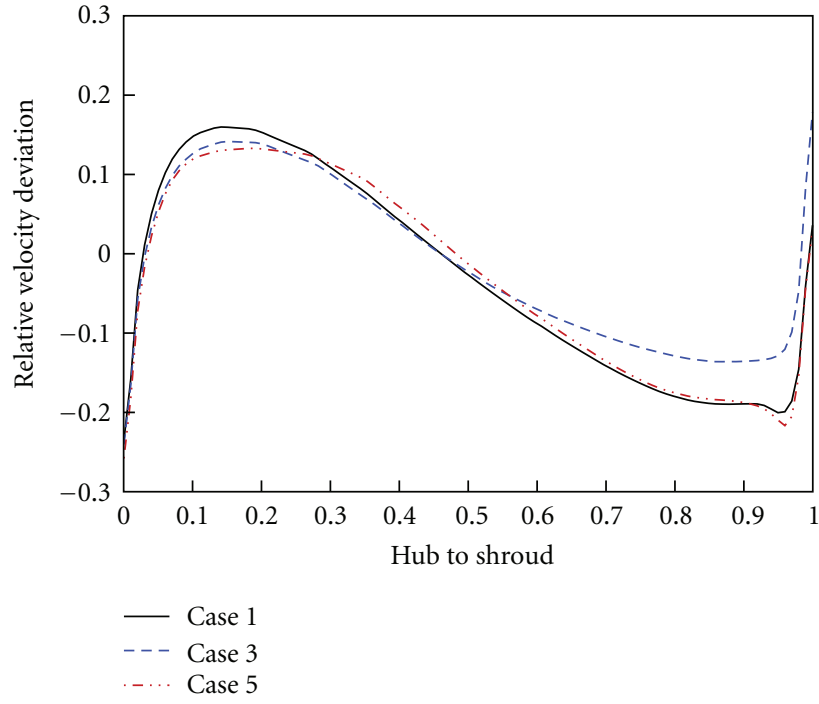

FIGURE 16: Relative deviation of relative velocity from hub to shroud at the impeller exit.

other words, the larger passage vortex played a key role in moving the wake region further toward the suction side for a system with a small tip clearance at the trailing edge.

The relative deviations from the mass-averaged relative velocity from the hub to the shroud at the impeller exit are further compared in Figure 16. All cases showed similar nonuniform flow patterns in the hub-to-shroud direction. That is, high relative velocities were present near the hub, whereas low relative velocities were found near the shroud. A $7 \%$ reduction in the flow deviation at $95 \%$ span was achieved in case 3 compared to the other two cases. This observation indicated that case 3 had a more uniform flow pattern in the axial direction due to the smaller wake region. In addition, reductions in the relative velocity gradient from the hub to the shroud produced a smaller secondary flow, which increased the impeller efficiency for case 3 .

Because the impeller outlet flow field significantly influences the diffuser inlet flow conditions, the flow inside the vaneless diffuser experiences severe distortions in the axial direction. The flow angle distribution from the hub to the shroud at the impeller exit for a compressor with a vaned diffuser must be considered in the design of advanced threedimensional diffusers [21].

Figure 17 shows variations in the flow angles from the hub to the shroud at a $110 \%$ impeller exit radius. Because the flow angle is measured from the circumferential direction, flows with small flow angles tend to be more circumferential. All three cases presented distorted flow patterns because the upstream impeller flow was strongly nonuniform in the axial direction. Differences in the flow angle between the hub and the shroud were at least $10^{\circ}$. Near the shroud, the wake flow, which had a small flow angle, remained in the diffuser inlet downstream of the impeller because the wake mixing process was incomplete. The diffuser flow pattern in case 3 was more homogeneous than in the other two cases in terms of the flow angle distribution in the axial direction due to the improved 


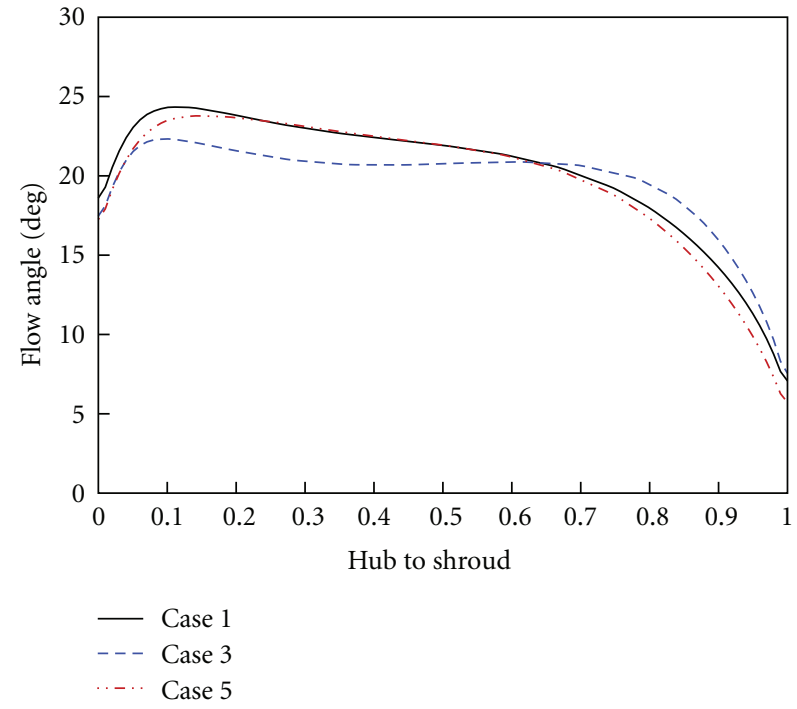

Figure 17: Flow angle distribution from hub to shroud at a $110 \%$ of the impeller exit radius.

uniformity of the flow field at the impeller exit, as confirmed in Figure 16. Therefore, a smaller tip clearance at the trailing edge provided a better potential for diffusion processes inside a vaneless diffuser than did a smaller tip clearance at the leading edge.

\section{Conclusions}

The effects of a nonuniform tip clearance on the flow fields and performance of a centrifugal compressor were analyzed. Six impellers with different tip clearance distributions were modeled numerically, and the flow fields were investigated in detail to identify the factors that contributed to variations in the performance and efficiency.

(1) Although impellers with reduced tip clearances at the leading or trailing edges performed better than the impeller with a original uniform tip clearance, a smaller tip clearance at the trailing edge reduced the overall tip leakage mass flow rate more effectively than a smaller tip clearance at the leading edge. Accordingly, a smaller tip clearance at the trailing edge lowered the mixing loss caused by interactions between the tip leakage flow and the main passage flow.

(2) A nonuniform tip clearance influenced the location of the wake region by modulating the interaction between the passage and tip leakage vortices, which rotated in the opposite directions and transported low-momentum fluid near the shroud. A small tip clearance at the trailing edge reduced the tip leakage vortex and increased the passage vortex, which consequently increased the transport of the wake region toward the suction side.

(3) A reduced tip clearance at the trailing edge produced a more uniform flow at the impeller exit both in the circumferential and in the axial directions due to a reduced wake region. Because the diffuser inlet flow was significantly affected by the upstream impeller outlet flow, decreasing the tip clearance at the trailing edge significantly improved diffusion processes inside the vaneless diffuser.

\section{Nomenclature}

$\begin{array}{ll}C: & \text { Absolute velocity } \\ D: & \text { Diameter } \\ \text { LE: } & \text { Leading edge } \\ \dot{m}: & \text { Mass flow rate } \\ P: & \text { Static pressure } \\ \text { PS: } & \text { Pressure side } \\ Q: & \text { Volume flow rate } \\ R: & \text { Gas constant } \\ s: & \text { Entropy } \\ S S: & \text { Suction side } \\ \text { SV: } & \text { Normalized secondary vorticity } \\ T: & \text { Static temperature } \\ \text { TE: Trailing edge } \\ U: \text { Blade speed } \\ W: \text { Relative velocity } \\ \phi: \quad \text { Flow coefficient }=Q /\left(D_{2}^{2} U_{2}\right) \\ \phi: \text { Design flow coefficient } \\ \gamma: \quad \text { Ratio of specific heat } \\ \eta: & \text { Isentropic total-to-total efficiency } \\ \mu: & \text { Work input coefficient } \\ \rho: & \text { Density } \\ \sigma: & \text { Entropy function } \\ \Omega: & \text { Impeller rotational speed } \\ \omega: & \text { Vorticity } \\ \bar{\omega}: & \text { Total pressure loss coefficient. }\end{array}$

\section{Subscripts}

0: Total condition

1: Impeller inlet

2: Impeller outlet

CL: Tip clearance

$\theta$ : Circumferential component.

\section{Acknowledgments}

The authors would like to thank the Institute of Jet Propulsion and Turbomachinery at RWTH Aachen for providing them with experimental data. This work was supported by the Defense Acquisition Program Administration, Agency for Defense Development [UD040006AD], and BK21.

\section{References}

[1] K. Brun and R. Kurz, "Analysis of secondary flows in centrifugal impellers," International Journal of Rotating Machinery, vol. 2005, no. 1, pp. 45-52, 2005.

[2] R. C. Dean and Y. Senoo, "Rotating wakes in vaneless diffusers," Journal of Basic Engineering, vol. 82, no. 3, pp. 563-570, 1960. 
[3] D. Eckardt, "Instantaneous measurements in the jet-wake discharge flow of a centrifugal compressor impeller," Journal of Engineering for Power, vol. 97, no. 3, pp. 337-345, 1975.

[4] M. Ishida and Y. Senoo, "On the pressure losses due to the tip clearance of centrifugal blowers," Journal of Engineering for Power, vol. 103, no. 2, pp. 271-278, 1981.

[5] Y. Senoo and M. Ishida, "Pressure loss due to the tip clearance of impeller blades in centrifugal and axial blowers," Journal of Engineering for Gas Turbines and Power, vol. 108, no. 1, pp. 3237, 1986.

[6] Y. Senoo and M. Ishida, "Deterioration of compressor performance due to tip clearance of centrifugal impellers," Journal of Turbomachinery, vol. 109, no. 1, pp. 55-61, 1987.

[7] C. Hah and H. Krain, "Secondary flows and vortex motion in a high-efficiency backswept impeller at design and off-design conditions," Journal of Turbomachinery, vol. 112, no. 1, pp. 713, 1990.

[8] M. Ishida, Y. Senoo, and H. Ueki, "Secondary flow due to the tip clearance at the exit of centrifugal impellers," Journal of Turbomachinery, vol. 112, no. 1, pp. 19-24, 1990.

[9] A. Goto, "Study of internal flows in a mixed-flow pump impeller at various tip clearances using three-dimensional viscous flow computations," Journal of Turbomachinery, vol. 114, no. 2, pp. 373-382, 1992.

[10] A. Goto, "The effect of tip leakage flow on part-load performance of a mixed-flow pump impeller," Journal of Turbomachinery, vol. 114, no. 2, pp. 383-391, 1992.

[11] G. Eisenlohr and H. Chladek, "Thermal tip clearance control for centrifugal compressor of an APU engine," Journal of Turbomachinery, vol. 116, no. 4, pp. 629-634, 1994.

[12] S. S. Hong, M. Schleer, and R. S. Abhari, "Effect of tip clearance on the flow and performance of a centrigugal compressor," in Proceedings of the ASME/JSME 2003 4th Joint Fluids Summer Engineering Conference (FEDSM '03), vol. 2, pp. 563569, Honolulu, Hawaii, USA, July 2003, Paper FEDSM200345094.

[13] C. Weiß, D. R. Grates, H. Thermann, and R. Niehuis, "Numerical investigation of the influence of the tip clearance on wake formation inside a radial impeller," in Proceedings of the ASME Turbo Expo 2003, Collocated with the 2003 International Joint Power Generation Conference (GT '03), vol. 6, pp. 681691, Atlanta, Ga, USA, June 2003, Paper GT2003-38279.

[14] M. Schleer and R. S. Abhari, "Clearance effects on the evolution of the flow in the vaneless diffuser of a centrifugal compressor at part load condition," Journal of Turbomachinery, vol. 130, no. 3, Article ID 031009, 9 pages, 2008.

[15] K. U. Ziegler, H. E. Gallus, and R. Niehuis, "A study on impeller-diffuser interaction: part I-influence on the performance," in Proceedings of the ASME Turbo Expo 2002: Power for Land, Sea, and Air (GT '02), vol. 5, pp. 545-556, Amsterdam, The Netherlands, June 2002, Paper GT2002-30381.

[16] K. U. Ziegler, H. E. Gallus, and R. Niehuis, "A study on impeller-diffuser interaction: part II-detailed flow analysis," in Proceedings of the ASME Turbo Expo 2002: Power for Land, Sea, and Air (GT '02), vol. 5, pp. 557-568, Amsterdam, The Netherlands, June 2002, Paper GT2002-30382.

[17] K. U. Ziegler, Experimentelle untersuchung der laufrad-diffusorinteraktion in einem radialverdichter variable geometriethesis, [Ph.D. thesis], RWTH Aachen, Aachen, Germany, 2003.

[18] A. Whitfield and N. C. Baines, Design of Radial Turbomachines, Longman Scientific \& Technical, 1990.

[19] R. Aungier, Centrifugal Compressors, ASME, New York, NY, USA, 2000.
[20] D. Japikse, Centrifugal Compressor Design and Performance, Concepts ETI, 1996.

[21] H. Krain, "Unsteady diffuser flow in a transonic centrifugal compressor," International Journal of Rotating Machinery, vol. 8, no. 3, pp. 223-231, 2002. 

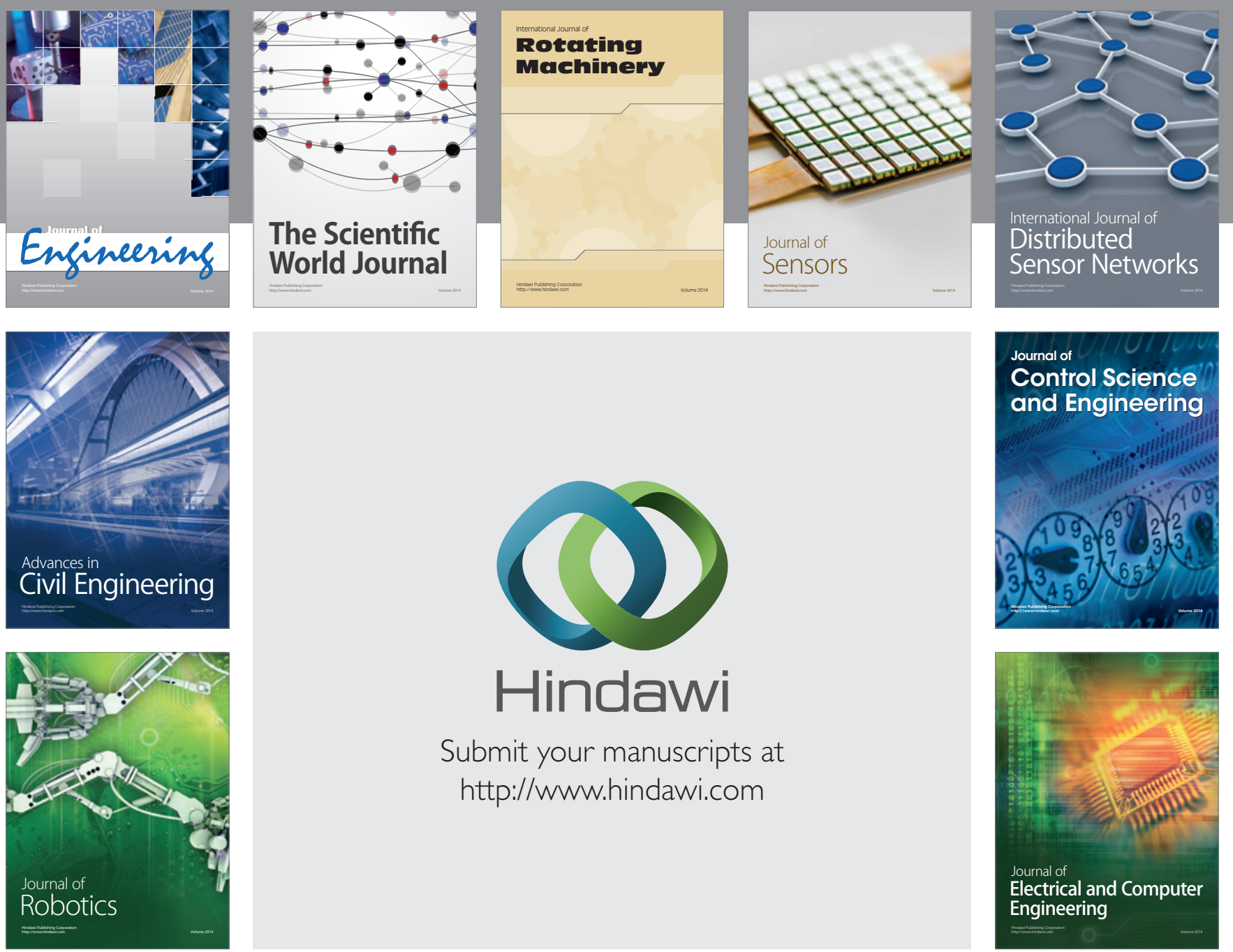

Submit your manuscripts at

http://www.hindawi.com
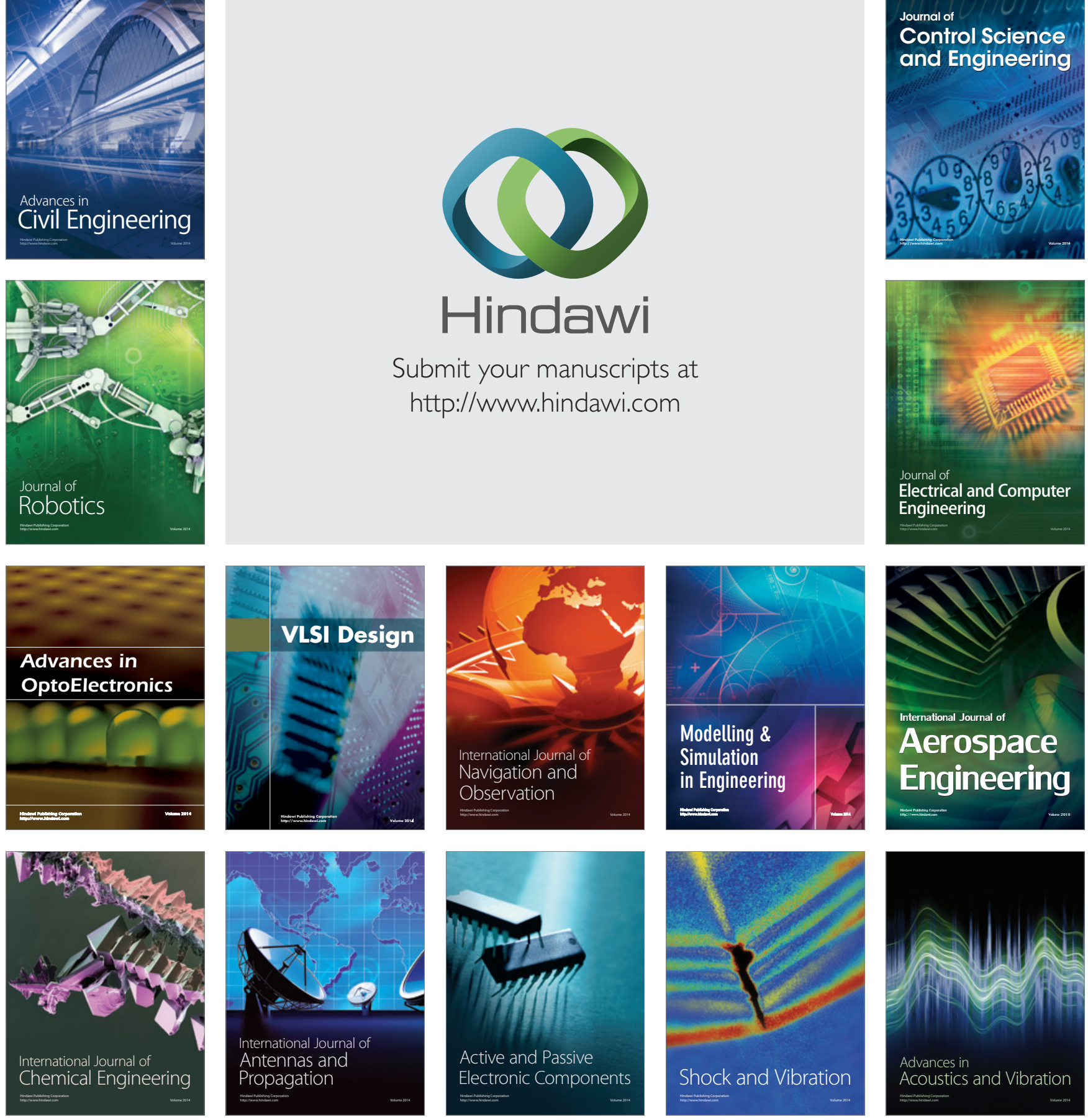